\title{
Maximizing Benefits from Hydropower: A Nepal Case
}

\author{
J anak Lal Karmacharya
}

$\mathbf{N}^{\circ}$ o other source of energy other than hydropower can deliver multi-pronged benefits. The development of hydropower can ensure energy security, provide food security and health security and, in addition, preserve environment, reduce greenhouse gas emission and create recreational facilities. It can also provide access to the sea for a land-locked country. With the world wide recognition, from World Summit on Sustainable Development to Bonn and Beijing Renewable Conferences through Third World Water Forum, that hydropower is the clean and renewable source of energy, the exploitation of hydropower is going to be a major activity to meet the Millennium Development Goal.

One of the important benefits that come out of the construction of dams for hydropower generation is flood control. In many cases, this benefit cannot be quantified in its totality; it is, however, a significant one as it saves precious life and resources. The construction of a storage hydro project, if properly executed on the basis of mutually agreed concept, can be instrumental in maintaining peace between transboundary countries.

\section{Socio-economic set-up of Nepal}

Nepal is one of the most populated mountainous countries in the world with the population density of 167 people per square kilometer. Basically it is a country based on an agrarian economy with about $80 \%$ of population engaged in agriculture. This sector contributes $38 \%$ to the national economy, which translates into $2.48 \%$ in agricultural growth, whereas non-agricultural growth is registered at $10.44 \%$. The heavy pressure is on agriculture and natural resources to support the growing population. The annual per capita GDP is estimated at USD 248. The human Development Indicator stands at 0.504. The life expectancy at birth is reported to be about 61 years and infant mortality is recorded at $69 \%$ in 2001 . The proportion of electrified households is $40 \%$.

The government has set a target of achieving annual economic growth of $8.3 \%$ by $2016 / 17$, out of which $5 \%$ growth is projected in the agriculture sector and $9.7 \%$ in non-agriculture sector. The population below the poverty line will be reduced to $10 \%$, with the growth reduced to $1.5 \%$. About 1700 thousand hectares will be brought under irrigation by the same year. Nepal is a land locked country, a factor that dominates the development scenario.

\section{Water resources use in Nepal}

Nepal is a land limited but water rich country. Its 6,000 rivers generates 224 billion cubic meter of surface run-off annually, which translates into more than $9,000 \mathrm{~m}^{3}$ of water per capita. This is far more than internationally recognized norm of $1,750 \mathrm{~m}^{3}$ per capita. However, because of the spatial and temporal variation in the availability of water, a few months and a few areas of the country are still water deficit. The uniform distribution of water over its territory is essential to avoid water stress situation This objective is met through adoption of Integrated Water Resources Management. The major components of integrated use are hydropower, irrigation, water supply and flood control and, to lesser extent, inland navigation, recreational use and fisheries.

\section{Hydropower - the way to poverty alleviation}

The rivers of Nepal with glacier, snow and monsoon feeding coupled with steep gradient, are estimated to have the potentiality of generating $83,000 \mathrm{MW}$ of electricity. With theload factor of $52 \%$, this translates into 1,500 kWh per capita of electricity for the present population. If this potentiality is fully exploited and sold at an average rate of six cents per $\mathrm{kWh}$, the resulting revenue generated will be to the tune of 23 billion USD per annum. Out of this theoretical potentiality, 43,000 MW have been proven to be technically and economically attractive through sound engineering studies.

In view of the importance of hydropower development for the overall economic development of the country, the Nepal Government has put specific emphasis on theimplementation of its National Water Plan (NWP). This plan envisages generating 2,100 MW by 2017 and 4,000 MW by 2027 . This, however, is a substantially downgraded target of 4,080 MW in 2017 and 11,568 MW in 2027. This was considered necessary to meet the value added requirement in the water and electricity sector to generate $6.5 \%$ economic growth. In the High Growth Scenario, with the assumption that the load factor will improve by $10 \%$ and operational expenses will drop by $10 \%$ due 
to economy of scale of plants, the projected generation is envisaged to be 6,275 MW in 2017 and 25,234 MW in 2027.

In comparison to the identified hydropower potentiality, the domestic electricity market of Nepal is very limited. Without entering into the export market, the benefits from hydro generation cannot be maximized. In the regional market, hydropower is going to play a significant role in addressing concern for energy security. The South Asia region is marching towards unprecedented economic growth. However, the supply of energy has been stumbling block. To face this challenge, Bangladesh, India, Pakistan and Sri Lanka are vigorously pursuing measures to diversify their traditional energy supply mix. Because of the high volatility of the oil market and the uncertainty associated with it, the role of hydropower assumes great significance. Hydropower, being capable of generating cheap and reliable peak energy, contributes to the stability of the system by stabilizing the supply frequency. This additional advantage of hydropower has led to the appreciation of the need to develop a Hydroelectric Master Plan for the South Asia Region encompassing India, Pakistan, Nepal, Bangladesh, Bhutan, Sri Lanka, the Maldives and newly entered Afghanistan. The objective of such a master plan is to facilitate an integrated planning mechanism to identify the hydropower sources that would meet the power needs of the region at an affordable cost. This will also help maximize the benefit from hydropower development and rationalize utilization of hydro resources. It will also bring hydropower to the center stage of the Regional Power Pool, envisaged to be created in the South Asia Association for Regional Cooperation (SAARC) framework.

Nepal and India have been traditional power exchange countries. To sustain India's rate of GDP growth requires considerable addition of electricity. The electricity deficit in India, particularly the peak deficit, is significant at $18 \%$. Hence, the Government of India has allowed a premium on the peak power in the vicinity of $50 \%$ of base electricity tariff. As reported earlier out of the 43,000 MW of proven capacity of Nepal, 22,000 MW will come from storage plants. Development of these schemes will maximize the benefit of Nepal Hydropower. In view of the mutual benefits to both Nepal and India and the need to mobilize private financial resources, India and Nepal have initialed a bi-national Power Trade Agreement. The proposed electric power agreement allows the governmental, semi-governmental and private enterprises of Nepal and India to enter into agreements for power trade. Agreeing parties may determine the terms and conditions of such agreements, including the quantum and parameters of supply, point of delivery and the price of supply. Such wide provisions in power trade agreement will facilitate the cross border flow of electricity during periods when each country needs the power. The time, location and duration of need are different in the two power systems. This introduces complimentarity in supply, thus maximizing the use and, therefore, the benefit of the hydropower.

Hydropower contributes to meeting both water and energy needs, including water for irrigation and drinking water. It usually works with a wider group of disciplines, to maximize hydropower's contribution to sustainable development.

\section{Irrigation - insuring food security}

As earlier mentioned, Nepal is basically an agriculture country with its contribution to the economy standing at $38 \%$ of GDP. Nepal has 2.64 million hectares of cultivable land, of which only 1.76 million ha $(66 \%)$ are irrigable. Irrigation facilities are available only for $60 \%$ of irrigable land, though less than one third of that land has round-the-year irrigation facility. This limited facility for irrigation and resulting unsatisfactory cropping intensity resulted, in 2003, in the production of 7.2 million tons of agricultural product-hardly sufficient to meet the minimum requirement of the nation.

The Nepal Government has embarked upon the plan to increase the total year-round irrigated area to $49 \%$, the cropping intensity to exceed $140 \%$ in yearround irrigated areas, and irrigation efficiency to 35\% by 2007. The corresponding figures for the year 2017 are $64 \%, 164 \%$ and $45 \%$, respectively. By 2027 , the targeted corresponding figures are $67 \%$ year-round irrigated area, an average cropping intensity of 193\% and an irrigation efficiency of $50 \%$.

The cost of implementing the plan, which may result in achieving the above target, is significant. In the short term (i.e., by 2007), the investment requirement is USD 293 million; in the medium term (2017) USD 1,405 million; and, in long term (2027), the figure goes up to USD 1,904 million. This totals USD 3,602 million over the next 20 years (at the 2003/ 04 price level). Raising this level of financial resources is a daunting task. The sector cannot generate enough money itself to finance the programme. The collection of water tariffs has a very poor record. Improvement has been envisaged with the target of achieving irrigation service contribution to $30 \%$ of operation and maintenance cost of the irrigation system by 2007, with further improvement in 2017 by increasing the figure to $45 \%$, and eventually reaching the figure of $75 \%$ by 2027 . This means that even for operation and maintenance, the irrigation system will not be self sustained, not to mention capital investment. It is here that the necessity to develop hydropower for multipurpose utilization 
assumes significance. Fortunately, the resource generation capacity of this sector is satisfactory and if the capital costs are shared between irrigation and power in a multipurpose development it will not only help address the problem of the irrigation sector but will also maximize the profits from hydropower development. Nepal has a number of projects that can meet this objective, such as Bagmati, Kankai, Sapt Kosi, Sunkosi, Karnali Bheri-Babai, Mahakali, etc.

\section{Flood control - reducing human suffrage}

One of the significant benefits that a dam construction gives is the flood control. This advantage becomes more important in the area where flash floods occur or the rivers are fed with monsoon rain. In Nepal floods usually occur because of the monsoon precipitation, glacial lake outbursts, cloud outbursts and coincidence of monsoon with increased base flow from snow and glacier melt. The damage and loss of living beings and assets are tremendous. There are many trans-boundary rivers that traverse from Nepal through India to Bangladesh causing extensive damage in multiple countries. One of Nepal's eastern rivers, the Kosi, is called 'the sorrow of Bihar', a populace state in northern India, because of the trail of devastation it leaves in Bihar every year after monsoon. The well documented damage caused by floods in Bangladesh in 1988 presents a grim picture, where loss of 2 million tons of crops, about 172,000 livestock and destruction of $1,990 \mathrm{kms}$ of embankment, $283 \mathrm{kms}$ of canals, 3,000 kms of national roads and $10,000 \mathrm{kms}$ of rural roads were reported. In Nepal the flood events of 1974, 1978, 1985 and 1987 were significant in terms of damage inflicted on the national economy. Studies conducted so far have identified about thirty reservoir sites in Nepal. The total effective water holding capacity of these reservoirs created by storage dam has been estimated to be about 77 billion $\mathrm{m}$.

Nepal is divided into five hydrological regions: will not only help mitigate floods but also help augment dry season flow by storing water in the reservoir to release during the dry season, thus improving irrigation potentiality and the mitigation of floods. However, to ensure the investment to implement such scheme, hydropower is the one component that alone can generate revenue. This kind of multipurpose development helps maximize the benefits of hydropower.

\section{Drinking water and sanitation - insuring health security}

Nepal is water rich. However its surface run-off heavily depends upon the monsoon, which is limited to four months a year. Although it is a small country with an area of $144,000 \mathrm{~km}^{2}$, the spatial distribution of run-off is uneven. Therefore the inter-basin transfer of water is necessary to meet the water needs of all regions of the country. Inter-basin transfer requires construction of dams to divert the water to water conveyance system.

Drinking water and sanitation services are basic needs of the population. At present around $50 \%$ of population has access to these services. By 2007, this service will be extended to $80 \%$ of population It is envisaged that by 2012, 90\% population will have access to water supply and basic sanitation facilities. $100 \%$ of the population will have these facilities by 2017. However; people will have to wait until 2027 to receive high quality services in these areas.

The main source of water supply has been surface run-off, which either has to be stored during the monsoon season and used in dry season or pump from groundwater. Due to the lack of storage hydropower projects, municipalities are relying heavily on groundwater extraction with an adverse impact on water table. Provision for drinking water in thestorage hydropower schemes or installation of powerhouses in drinking water schemes, whereinter-basin transfer is executed, not only maximizes the benefit of hydro Mahakali River Basin, Karnali River Basin, Gandak River Basin, SaptKosi River Basin and Southern River Basin. The holding capacity of each of these basins is given in Table 1.

The storage capacity constitutes almost $70 \%$ of total monsoon flow. Multipurpose and optimal utilization of these water resources by constructing high dams

\begin{tabular}{|c|c|c|}
\hline BASIN & $\begin{array}{c}\text { HOLDING CA PACITY OF RESERVOIR } \\
\text { (million cubic meters) }\end{array}$ & $\begin{array}{c}\text { HOLDING POTENTIAL OF } \\
\text { MONSOON RUNOFF (\%) }\end{array}$ \\
\hline Mahakali & 6,040 & 43.2 \\
\hline Karnali & 34,243 & 123.7 \\
Gandak & 17,830 & 55.1 \\
\hline Sapta Kosi & 13,760 & 44.6 \\
Southern River & 5,221 & 92.9 \\
\hline
\end{tabular}

Table: 1 Holding capacity of reservoirs in each basin 
schemes but also helps lighten the financial burden of drinking water projects. Provision of safe drinking water also ensures the health security of the population

\section{Hydropower and cost of imported energy}

Nepal does not have any fossil fuel reserve nor coal mining. Technological development of the country does not allow development of nuclear power. The development of alternative energy such as solar or wind is also limited due to the cost involved in such development. Hence, for all commercial energy needs, Nepal has to depend either on imported fossil fuels or indigenous hydropower. The industrial, transportation and urban household energy needs are predominantly met by imported fuel. Hydropower has been exploited only in a limited quantity because of the lack of investment.

Meanwhile, the importation bill of fossil fuels is rising, not so much because of an increase in demand but because of skyrocketing prices. The demand on petroleum products has remained more or less at the samelevel, largely because of political instability, which has contributed to a slow down in economic activities and, to some extent, to the increase in hydropower generation. However, the price of petroleum products has more than doubled in the past decade (see Table 2). The costs are given at the price level of J uly 2006.

In a small economy such as Nepal, pressure on the foreign currency reserve, because of the petroleum products bill, is substantial. It is here that theimportance of hydropower development plays a vital role not only in terms of lessening the pressure on foreign currency reserves, but also in ensuring energy security against uncertainty in supply as well volatility in oil market prices.

The Nepal Rastra Bank, the central bank of Nepal, has reported a record foreign currency deposit of about USD 2 billion this year. The nearly USD 300 million fuel importation bill per annum is a substantial chunk of the foreign currency saving.

Topographically, Nepal is brick shaped with eastwest prolongation and north-south width presents a narrow strip with elevation differences of more than $8,000 \mathrm{~m}$ within a narrow width of about $200 \mathrm{kms}$. If Nepal develops a transportation system run by electricity generated from hydropower, it can save substantial portion of petroleum product importation bill of USD 138 million. This is 23\% of annual export. A transportation system that could bring about this benefit could be based on hydroelectricity driven east- west railway networks, north-south cable cars and inter- and intra-city tramways and trolley buses. Theintroduction of such systems will derive maximum benefit from hydropower, and change the face of nation. As an additional benefit it will also drastically reduce dependency on the third country, which Nepal has to rely upon, being a land-locked country. Such a hydroelectricity driven transportation system would also greatly enhance national security.

\section{Environment and additional benefit from hydropower}

World climate change has been a phenomenon of global concern. One of the major agents of climate change has been the greenhouse gas (GHG) emission by various power generating plants. After the Kyoto protocol signed by 134 countries, it has been the obligation of the each signatory country to help reduce the emission of GHG within a certain period. Globally it is expected that GHG emissions will be reduced by 2010 by $10 \%$ from the present level. To meet this international obligation, a new kind of trade-Carbon Trade-has started through Clean Development Mechanism (CDM). Hydropower, being

\begin{tabular}{|c|c|c|}
\hline YEAR & $\begin{array}{c}\text { IMPORTED QUANTUM } \\
\text { IN KL }\end{array}$ & $\begin{array}{c}\text { AMOUNT } \\
\text { IN USD }\end{array}$ \\
\hline $1999 / 00$ & 877,856 & 121 million \\
$2000 / 01$ & 941,914 & 190 million \\
$2001 / 02$ & 896,324 & 241 million \\
$2002 / 03$ & 890,609 & 312 million \\
$2003 / 04$ & 879,455 & 313 million \\
$2004 / 05$ & $n / a$ & 291 million \\
\hline
\end{tabular}

Table 2: Importation of fuel and fuel bill of Nepal

not related with the emissions-related environmental concerns and being the cleanest source of power generation, not only helps the environment but also generates revenue by entering into this trade, thus maximizing the benefit. Across the southern border, coal- and gas/ diesel-fired thermal plants are the main sources of power generation. A World Bank study of the neighboring state of Bihar, India, estimates the emission at levels of $1.23 \mathrm{~kg} / \mathrm{kwh}$ of carbon dioxide, $7.2 \mathrm{~kg} / \mathrm{kHz}$ of nitrogen monoxide, and $8 \mathrm{~kg} / \mathrm{kwh}$ of sulphur monoxide. Nepal's 10 medium and big hydropower plants have the generating energy capacity of about 40,000 GWh. Assuming that these 10 hydropower projects will displace a mix of coalfired and liquid- fuel thermal plants with similar emission levels, the 40,000 GWh combined annual 
generation would reduce GHG emission by 680 million tons. With the prevailing average rate of USD 5 , the trade would generate about USD 3.4 billion per annum. If these developments were translated into reality, it would not only help meet the global target of reducing GHG emissions but also contribute to the national economy, not only of Nepal but also of neighboring countries.

\section{Hydropower and poverty alleviation}

In a country which is hydropower rich, poverty alleviation hinges on the development of this resource. The potential impact is astonishing in a small country with no competitive source on income generation. In Bhutan, for example, a country of about half a million population, the development of hydropower has been dramatically changed by the construction just two hydropower plants with combined capacity of 1,380 MW. As a result, it is expected that the per capita income will go up from USD 760 to 1,320. In Nepal, theimpact of hydropower development may not be that dramatic, but it has been established that the hydropower sector is the driving sector in economic development and a major resource to alleviate poverty. A macro-economic study has concluded that in order to eradicate absolute poverty in households, the country needs to register $8 \%$ economic growth rate. This will help to bring the level of percentage of population below poverty line to $10 \%$ and by 2027 there will be no household in absolute poverty. No other sector of economy other than hydropower is in a position to help attend to this goal, as the required quantum of $25,000+$ MW by 2027 that need to be developed to achieve this target is ready for exploitation at short notice, and the market is available. Thus, the solution of poverty alleviation is closely linked with hydropower development in Nepal.

\section{Wrapping-up}

Based on the recommendation and statement of Third World Water Forum on Water and Energy, some pertinent observations can be made:

- Water and energy must be integrated as far as possible to maximize the benefit of hydropower development. Multipurpose infrastructures offer the advantage of shared cost and benefit.

- Hydropower contributes to meeting both water and energy needs.

- Hydropower with storage reservoir is the most flexible energy technology in terms of power generation; it can generate power exactly when it is needed, providing back-up for intermittent sources such as wind power and allowing thermal plants to operateat their best efficiency, thus further reducing greenhouse gas emissions.

Janak Lal Karmacharya holds a $\mathrm{PhD}$ degree in hydrology and hydraulics, and has been working in the power sector, especially in hydropower development, for more than three and half decades. Dr. Karmacharya has participated and led studies, design and construction of hydropower schemes and development of hydropower policy in Nepal and abroad. Heis a past Managing Director of the Nepal Electricity Authority, and is currently Head/ Hydro Business, Clean Energy Development Bank, a member of the Steering Committee of the Dams and Development Project under UNEP, and a board member of the International Hydropower Association. He has also served as a consultant to the World Bank and the USAfunded South Asia Regional Initiative/ Energy Program.

Corresponding address: janak.karmacharya@gmail.com

\section{References}

WB (World Bank), 2006, Economic Growth in South Asia, Washington, DC: The World Bank.

WECS (Water and Energy Commission Secretariat), 1995, Energy Resources Base of Nepal, Kathmandu: WECS.

Kuensel on-line Bhutan Daily, 28 J une 2006, Thimphu, Bhutan. URL: www.kuenselonline.com

Prabhat (J ournal of the Nepal Oil Corporation, Kathmandu), 2004.

SARI/ E (South Asia Regional Initiative/ Energy Program), 2005, Regional Energy Security for South Asia, New Delhi: SARI/E.

MOWR (Ministry of Water Resources/ Nepal) and MOI (Ministry of Irrigation/ Bangladesh), 1989, Report on Flood Mitigation Measures and Multipurpose Use of Water Resources, Kathmandu: MOWR/ Nepal, and Dhaka: MOI, Water Development and Flood Control Division.

TWWF (Third World Water Forum), 2003, The3rd World Water Forum Final Report, Kyoto: TWWF Secretariat.

WECS (Water and Energy Commission Secretariat), 2000, Water Sector Strategy Formulation, Kathmandu: WECS.

WECS (Water and Energy Commission Secretariat), 2005, National Water Plan, Kathmandu: WECS. 